\title{
Effectiveness of Type of Feedback and Frequency on Digital Game- Based L2 Vocabulary Acquisition
}

José Ramón Calvo-Ferrer, Universidad de Alicante, Spain

\begin{abstract}
The frequency of word exposure in teaching materials, along with corrective feedback, has often been identified as a powerful variable in the learning of vocabulary in a foreign language. The effect of the number of times an action is presented as accurate in digital game-based language learning scenarios (i.e., knowledge of correct response [KCR] feedback) however remains under-investigated. This study aims to analyse the learning of L2 mobile operating system terminology by a group of students of English as a foreign language by using the data collected by the video game The Conference Interpreter in order to identify the predictive strength of term frequency (times a term is shown), KCR feedback (times a correct answer is provided), and corrective feedback (times a term is shown as incorrect) regarding short and long-term L2 vocabulary learning. The regression analysis performed showed that the factor 'KCR feedback' may be a positive predictor of short-term vocabulary learning, whereas the other factors seemed to have no statistical effect at any significant level.
\end{abstract}

\section{KEYWORDS}

Effectiveness, Feedback, Frequency, Language Learning, Video Games

\section{INTRODUCTION}

The study of vocabulary has attracted a great deal of attention in Computer-Assisted Language Learning (CALL) research (Chiu, 2013). Following a growing interest in video games as potential tools for teaching and training, different CALL studies have focused on the effect of digital game-based learning (DGBL) on language gains (see Xu, Chen, Eutsler, Geng, \& Kogut, 2019). A number of experimental designs have attempted to understand lexical development in second or foreign language (L2) scenarios (see Hung, Yang, Hwang, Chu, \& Wang, 2018). Besides L2 learning possibilities afforded by DGBL, video games may be used to monitor progress and track gaming data in order to predict learning outcomes (see Illanas Vila, Calvo-Ferrer, Gallego Durán, \& Llorens Largo, 2013). Such information provides researchers with opportunities to understand their effect on cognitive processes such as the learning of vocabulary in a foreign language.

\section{LITERATURE REVIEW}

\subsection{Word Exposure Frequency and Vocabulary Learning}

Vocabulary acquisition has been traditionally considered central to second language learning. Rivers (1983) states that it is vocabulary, rather than grammar, that is needed to get meaning across in basic 
communicative competence contexts, and McCarthy (1990) suggests that it is words, independently of grammar or syntax, that conveys meaning and therefore communicate ideas. As Chambers (1999) points out, vocabulary learning is sine qua non to language learning, without which communication is bound to be unsuccessful (Vermeer, 1992). More recent studies suggest that second language learning is largely dependent on vocabulary (Restrepo Ramos, 2015) and that '[1] earners need large vocabularies to successfully use a second language, and so high vocabulary targets need to be set and pursued' (Schmitt, 2008, p. 353). Learning has often been explained in relation to the number of times a second-language learner encounters any given word. In line with this, Mason and Krashen (1997) and Grabe and Stoller (1997) state that exposure to vocabulary leads to language learning. Also, Meara (1992) developed a model for English as a Second Language vocabulary testing in which vocabulary growth correlated with general frequency of occurrence, establishing a distinction between high-frequency and low-frequency words. Milton endorses Meara's frequency model of learning and claims that, as a general rule, "the more frequent a word is, the more likely it is to be learned' $(2009$, p. 26), which is supported by recent studies suggesting that '[v]ocabulary learning occurs over time and is dependent on learner actions and on multiple encounters with a given item' (Godwin-Jones, 2018, p. 1).

However, while general word exposure frequency is assumed to bear an impact on L2 vocabulary gains, there seems to be no consensus on the number of times a word needs to appear before it is assimilated. Saragi, Nation and Meister (1978) and Rott (1999) state that a word is learnt after six encounters. Jenkins, Stein and Wysocki (1984) identified that $25 \%$ of the learners in their study acquired a word after it had been encountered ten times, whereas Herman, Anderson, Pearson, and Nagy (1987) indicate that full acquisition of word occurs after 20 encounters. Regarding DGBL contexts, Chen and Hsu (2019, p. 11) believe that 'repetitive exposure (i.e. more than six times) to words also has a positive influence on incremental vocabulary acquisition in gaming'. However, as Nation and Gu (2007) indicate, not all words are learnt the same way. Ellis and Beaton (1993) state that nouns and adjectives are easier to learn than verbs and adverbs, whereas Laufer (1990) identifies a series of 'intralexical factors' related to form and meaning stemming from the word itself which may facilitate or hamper the learnability of lexical items, namely pronounceability, orthography, length, morphology, similarity of lexical forms, grammar, and semantic features. In fact, recent studies suggest that other factors like saliency (the relevance of a word within a given context) and distribution (the way occurrences are distributed over time) may actually have a greater impact on L2 vocabulary learning processes than frequency (Alcaraz-Mármol, 2010, 2015).

\subsection{Digital-Game Based Language Learning}

Video games have been extensively employed in educational contexts upon the premise that they engage students and provide instant feedback, which, according to some authors, makes them optimal teaching and learning tools (Cornillie, Clarebout, \& Desmet, 2012; Schrader \& McCreery, 2008; Warburton, 2009). It is argued that, if properly designed, video games facilitate long-lasting learning (Nesselhauf \& Tschichold, 2002; Rama, Black, van Es, \& Warschauer, 2012) and establish low-anxiety environments (Melchor-Couto, 2017) that can reduce students' fear of making mistakes (Nemitcheva, 1995). Computer games are increasingly being implemented not only as educational tools in the classroom, but also as training devices in an array of environments such as healthcare (see Skiba, 2008), science and technology (see Liu, Rosenblum, Horton, \& Kang, 2014; Mayo, 2007), military (see Ricci, Salas, \& Cannon-Bowers, 1996; Whitehill \& McDonald, 1993), and so forth. Their use is also frequent in L2 learning since they replicate sociocultural conditions (Anderson, Reynolds, Yeh, \& Huang, 2008; Schwienhorst, 2002) and provide 'sheltered contexts for controlled exposure to, and practice with, input that may be repetitive and redundant' (Reinhardt, 2017, p. 206), which 'increase[s] student enthusiasm, lower[s] anxiety, and improve[s] willingness to communicate' (Reinders \& Wattana, 2011, p. 25). Such affordances may trigger the underlying cognitive processes that promote L2 learning (Hitosugi, Schmidt, \& Hayashi, 2014), as supported by different experimental 
research designs (Amoia, Gardent, \& Perez-Beltrachini, 2011; Chen, Tseng, \& Hsiao, 2018; Connolly, Stansfield, \& Hainey, 2011; Huyen \& Nga, 2003; Hwang \& Wang, 2016; Li \& Chiu, 2011; Miller \& Hegelheimer, 2006; Ranalli, 2008; Sandberg, Maris, \& Hoogendoorn, 2014; Yip \& Kwan, 2006) and meta-analysis studies on digital game-based L2 vocabulary learning: Chiu, Kao and Reynolds (2012) advocate for the development of games that provide students with meaningful and engaging situations to use language, whereas Tsai and Tsai conclude that 'the use of digital games can effectively motivate and enhance students' L2 vocabulary learning.' (2018, p. 355).

\subsection{Feedback in Language Learning Scenarios}

Among the characteristics of video games is their ability to provide instant (as opposed to delayed) feedback, which has often been identified as one of the most salient affordances in digital game-based learning scenarios (see Gee, 2003; Malone, 1981; Sykes \& Reinhardt, 2012). Feedback in video games typically consists of cues showing whether any action pursuant to the game goals is correct or incorrect. It may positively reinforce in-game choices by informing the player of the successful completion of a task, but it may also highlight errors to raise players' awareness either implicitly or explicitly throughout direct intervention, taking thus the form of corrective feedback. As in video games, second language learners can be faced with positive evidence and negative evidence. Whereas positive evidence 'provides learners with models of what is acceptable in L2,' negative evidence 'provides learners with information as to what is unacceptable in L2' (Kim, 2004, p. 1). In the field of second language learning negative evidence is often referred to as corrective feedback, i.e. the 'responses to a learner's nontargetlike L2 production' (S. Li, 2010, p. 309), which may consist of 'a) an indication that an error has been committed, b) provision of the correct target language form, or c) metalinguistic information about the nature of the error, or any combination of these' (Ellis, Loewen, \& Erlam, 2006, p. 340). Such feedback may be conveyed implicitly or explicitly: explicit corrective feedback provides learners with metalinguistic information about unacceptable models in L2, while implicit corrective feedback is merely informative of inaccurate linguistic utterances in L2. In other words, the former provides a correction for unacceptable models and the latter merely highlights that an error has occurred.

Whilst studies in second-language learning have typically put an emphasis on corrective feedback (see Ellis et al., 2006; Kim, 2004; Li, 2010; Russell \& Spada, 2006), the effect of other types of feedback common to computer-mediated learning contexts such as knowledge of correct response, which 'informs the learner of the correct answer to a specific problem, with no additional information' (Shute, 2008, p. 160) has been often disregarded. In fact, although KCR feedback has been proven to improve the efficiency of learners on transfer tasks and to increase motivation (Corbalan, Kester, \& van Merriënboer, 2009), its effect on digital game-based vocabulary learning remains unexplored. Finally, even though feedback has been widely assumed to promote learning gains, some authors claim not only that 'measurement of feedback effectiveness is difficult and perhaps impossible' (Price, Handley, Millar, \& O'Donovan, 2010, p. 287), but also that feedback does not uniformly improve performance (Balcazar, Hopkins, \& Suárez, 1985) since it merely offers information which 'as such has no necessary consequences at all' (Latham \& Locke, 1991, p. 224). Feedback interventions, it is claimed, 'do not always increase performance and under certain condition are detrimental to performance', its effects being 'moderated by the nature of the task' (Kluger \& DeNisi, 1996, p. 275).

\subsection{Current Study}

All in all, while it is a common notion that video games may help develop foreign language skills, that feedback has an impact on learning, and that word exposure frequency influences vocabulary acquisition, it is less clear how frequency and type of feedback affects the learning of vocabulary that goes on in digital game-based learning scenarios. As Chen and Hsu (2019, p. 15) suggest, although serious games may lead to L2 vocabulary learning, '[i]t would be interesting to further explore whether different levels of frequency affect different types of vocabulary knowledge in the 
context of gaming', this is, to 'examine the relationship between vocabulary knowledge [...] and the number of occurrences [...] of target items.' Since video games can offer insight into L2 vocabulary learning processes and feedback effectiveness, this study aims to build on previous research (CalvoFerrer, 2017), which compared learning outcomes between traditional instruction and digital gamebased learning, by analysing data collected by The Conference Interpreter in order to investigate the predictive strength of term frequency (times a term is shown), KCR feedback (times a correct answer is provided), and corrective feedback (times a term is shown as incorrect) regarding short and longterm L2 vocabulary learning.

The Conference Interpreter (Calvo-Ferrer et al., 2013) is a gaming application which simulates a conference where the players have to act as interpreters by using the correct terminology. This is done by listening to different talks in English and completing the translation into Spanish by choosing, as in traditional multiple-choice exercises, the relevant terminology that appears at the bottom of the screen with a time lag of 1.5 seconds. If the terms chosen are correct, they blend in with the text, thus providing knowledge of correct response (KCR) feedback and letting the student identify them as accurate. If they are incorrect, a cross-out appears in the gap, showing the player that their answer is inaccurate (see Figure 1). However, correct terms are not prompted in the event of inaccurate term selection, providing only implicit corrective feedback. The main objective of the game is to develop students' terminology and interpreting skills such as divided attention, short-term memory and anticipation (Mitchell, 2001; Pérez-Luzardo Díaz, 2005). Three key aspects were taken into account during the development of The Conference Interpreter whilst observing different tools for the evaluation of serious games such as the RETAIN model (Gunter, Kenny, \& Vick, 2008), the ARCS instructional design model (Keller, 1987) and the EGameFlow scale (Fu, Su, \& Yu, 2009) to ensure the relevance and adequacy of its contents.

First, the application was designed with the foremost objective of being an engaging and entertaining tool, in accordance with the principles of game design and player engagement theories (see Koster, 2005; Salen \& Zimmerman, 2004; Schell, 2008) while underpinning its learning informational content since, as Reinhardt (2019, p. 200) suggests, 'metalinguistic knowledge about language, if that is the goal of instruction, may not develop without some direct focus'. Several prototypes were released and tested by second language learners other than the participants in the experiment and their feedback analysed in order to ensure the highest possible level of user playability and engagement. This resulted in the implementation, for example, of different rewards, power-ups and score tables (see Figure 2) in the final version of the video game. Second, it was designed to provide instructors with the possibility of creating new materials. Thus, the game allows the input of audio and text of any given complexity that will automatically result in new materials for second language learning and interpreter training. Third, bearing in mind the pertinence of data mining as a means to predict learning outcomes, The Conference Interpreter was designed as a tool to monitor learner actions and collect data generated during game play, such as information about the terms that appear throughout the different levels of the game and the students' response to each one of them, classified not only as correct/incorrect, but also in terms of actual answers provided, time lapse between term appearance and students' input, power-ups used (if any), or level played (see Figure 3). Spreadsheets containing data are automatically generated and may be used for data mining analysis leading to prediction of students' behavioural patterns and learning outcomes.

Based on the literature review, the questions 'What is the effect of frequency and feedback on L2 vocabulary learning?', 'Are frequency and feedback predictors of digital game-based vocabulary learning success?', and 'Does frequency have a greater impact on L2 vocabulary learning than feedback?' were examined. In the hope of addressing them, the hypotheses of the study were formulated as follows:

H1: The more times a word is encountered by a student in a digital game-based scenario, the more likely it is to be learnt. 


\section{Figure 1. Screenshot from The Conference Interpreter}

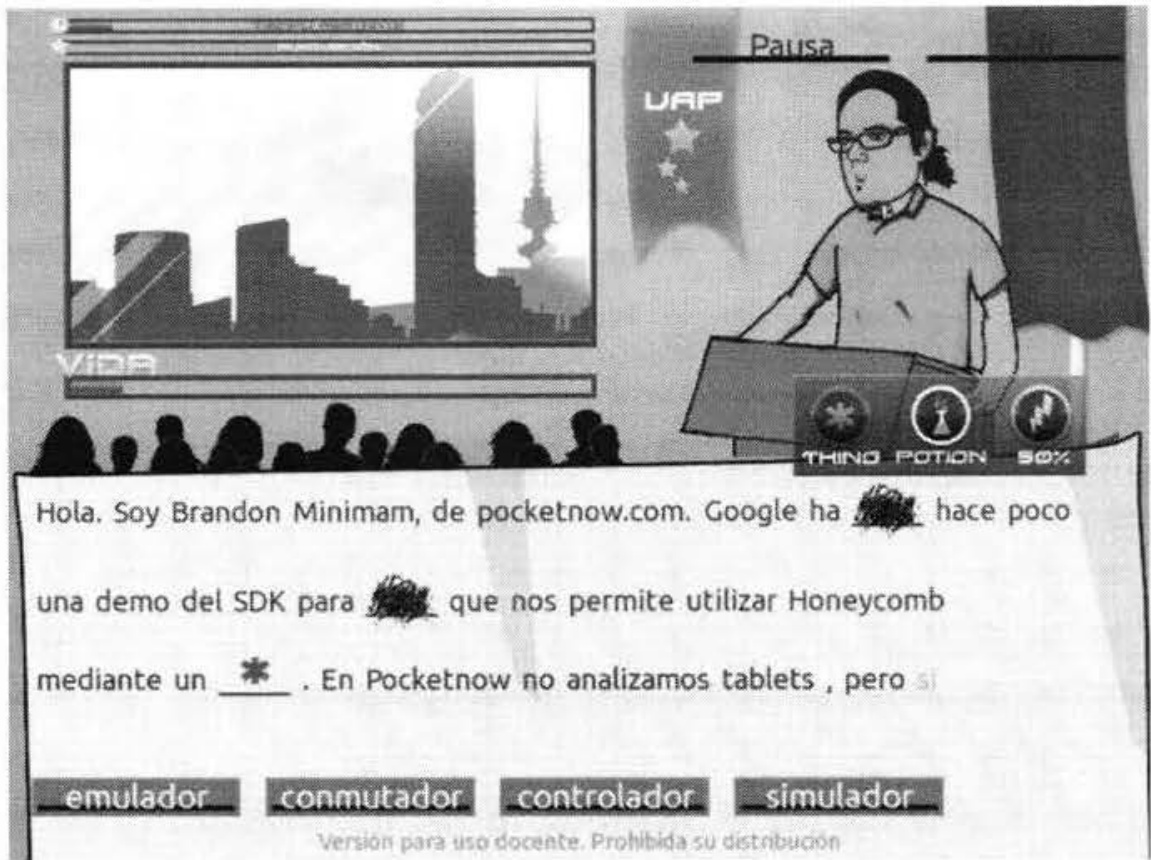

Figure 2. Level debriefing screen

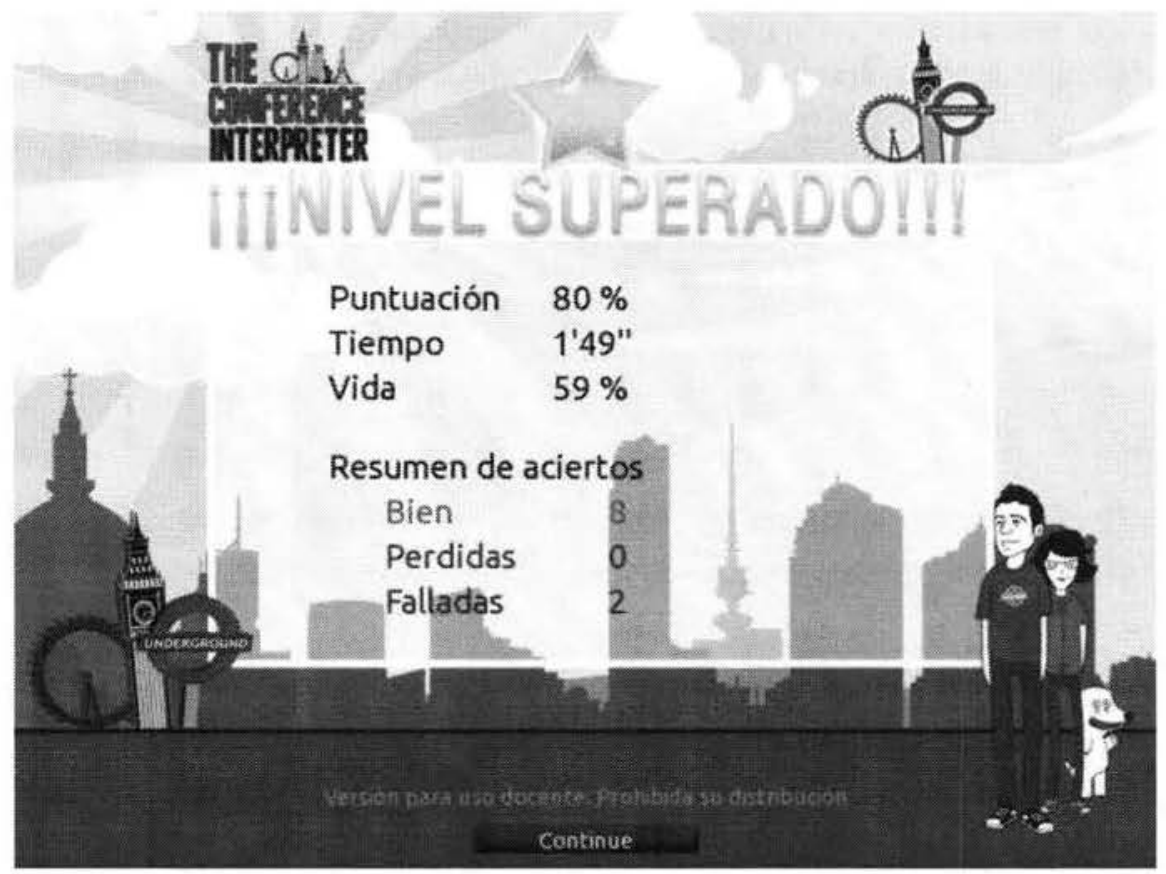


H2: The more times a word is presented as accurate in a digital game-based scenario, the more likely it is to be learnt.

H3: The more times a word is presented as inaccurate in a digital game-based scenario, the more likely it is to be learnt.

\section{METHOD}

\subsection{Sample}

The participants for this study were 67 students of English as a Second Language from the first year of the degree in Translation and Interpreting at the University of [Blinded] holding a B2-C1 level of English (Common European Framework of Reference for Languages), as determined by testing. In total, 55 female and 12 male L1 Spanish speakers aged between 17 and $28(M=18.856, S D=$ 1.989) participated in the experiment.

\subsection{Target Items}

The gaming application included different talks which contained specialised terms on mobile operating systems ${ }^{\prime}$. Players interacted with the game by listening to such talks in English and selecting, among the different options, the correct term for the gapped translation appearing at the bottom of the screen. As in previous studies (see Earl, 1970; Kageura \& Umino, 1996; Pazienza, Pennacchiotti, \& Zanzotto, 2006), most specialised terms in the game were noun phrases. Twenty-five of them were selected as target words in this study: API, bezel, border, browser, come stock, core, CPU, EAL, emulator, landscape, manager, multitasking, OEM, port, preview, processor, release, rendering, run, SDK, shortcut, stream, UI, unlock, and widget.

\subsection{Procedure}

The experiment was carried out in four different sessions at the University of [Blinded]. In the first session, students enrolled in the module [Blinded] from the degree in Translation and Interpreting were asked to individually complete a paper-based knowledge test on mobile operating systems terminology under the supervision of their teachers. As in the game, students needed to provide an accurate translation from English into Spanish for each of the target items, which were presented with sufficient context in order to ensure correct understanding (see Appendix). Students also took an English as a Foreign Language test ${ }^{2}$ consisting of 25 questions to determine their English skills, since language aptitude has been traditionally considered to influence language learning (Gardner, Moorcroft, \& Metforda, 1989) and previous research identified positive correlations between L2

Figure 3. Data collected by the gaming application
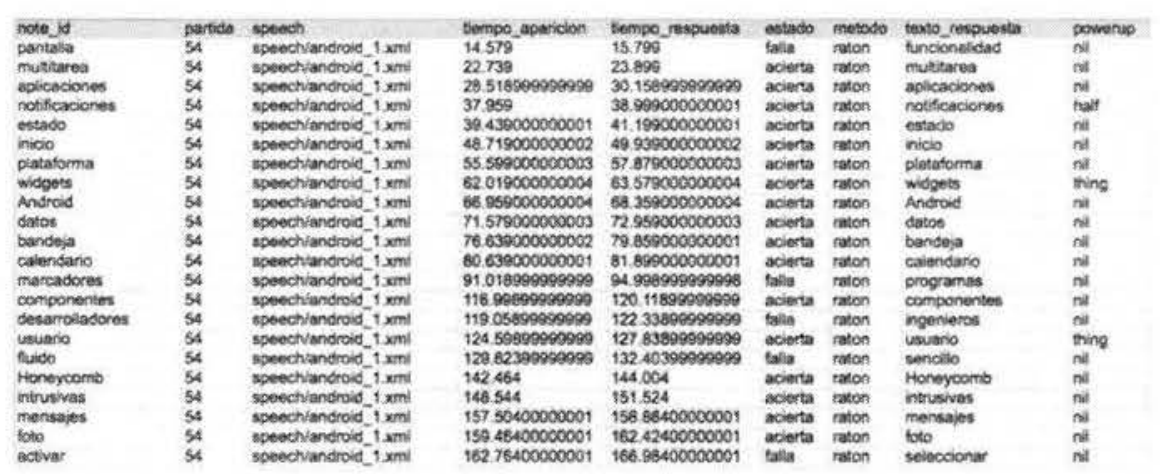
vocabulary skills and video game playing (Sundqvist, 2009; Sylvén \& Sundqvist, 2012). As Elgort (2018, p. 19) states, 'research into L2 vocabulary acquisition shows that vocabulary development progresses differently for low-and high-proficiency learners, even when level-appropriate L2 input is used'. One week following completion of the pre-test, students interacted individually with the video game during 3.5 hours in sessions 2 and 3 , which took place on consecutive days, while in the presence of their teachers, who, however, did not provide any help other than setting up the materials and making them ready for student use. Students were encouraged to complete all levels in the game aiming for high scores. They were also allowed to pause the game and/or leave the room if they felt they needed to take a break from interacting with the gaming application. In the last 30 minutes of session 3, students took the test on mobile operating systems terminology again. Finally, session 4, in which students completed the test a third time while in the presence of their teachers, was held six weeks after the treatment, in line with previous literature (see Brett, Rothlein, \& Hurley, 1996). In order to prevent memorisation, questions were arranged in a different order. Also, right answers were not made available nor any type of feedback was provided regarding students' responses.

\subsection{Data Collection and Analysis}

Since gameplay design choices have an influence on engagement and presence (Caroux, Isbister, Le Bigot, \& Vibert, 2015), The Conference Interpreter allows for players' non-linear exploration of the different game levels. This results in unique interactions with the game in terms of gaps seen and engaged with. Among the gaps players interacted with were the twenty-five target items appearing in the pre-test, post-test and delayed test $(M=64.72, S D=13.686)$, as Figure 1 shows. In line with the hypotheses of the study, data regarding the number of times (i) a student engaged with a target item, (ii) a correct answer therefor was provided, (iii) and an incorrect answer therefor was provided were collected and analysed. Mean scores for such data are shown in Table 1. For the purposes of this study, short-term L2 vocabulary learning was calculated as the difference in pre- $(M=7.51, S D$ $=3.373)$ and post-test $(M=13.64, S D=3.311)$ scores, whereas long-term $L 2$ vocabulary learning was calculated as the difference in pre- and delayed test $(M=10.82, S D=3.316)$ scores.

In order to evaluate whether frequency and type of feedback could account for any betweensubject differences in L2 vocabulary learning, correlational and linear regression analyses were carried out. First, bivariate correlations were computed to explore relationships between variables. Several statistically significant correlations, which are presented in Table 2, were found, leading up to multivariate linear regressions, which aimed to look into the predictive strength of (i) the number of times a target item is encountered in The Conference Interpreter video game (frequency), (ii) the number of times an option provided for such an item is identified as correct by the player (knowledge of correct response feedback), and (iii) players' L2 skills (English proficiency) on digital gamebased L2 vocabulary learning, both in the short and in the long run. Eventually, the number of times players realise an option provided in the video game is inaccurate and no correct answer is prompted (implicit corrective feedback) was not included in the multiple regression analyses since, as Table 1

Table 1. Mean scores for the model variables

\begin{tabular}{|c|c|c|}
\hline Factor & M & SD \\
\hline Proficiency in English & 18.87 & 2.752 \\
\hline Times a term is shown & 64.72 & 13.686 \\
\hline Times a term is shown as correct & 44.96 & 8.362 \\
\hline Times a term is shown as incorrect & 17.64 & 9.107 \\
\hline Times a term is ignored & 2.12 & 2.358 \\
\hline
\end{tabular}

Note: $n=67$ for all analyses. 
shows, the correlational analysis suggested there is no interaction between such type of feedback and learning outcomes owing to practice with the video game. These analyses were performed using the SPSS 22.0 statistical software with the significance level set at 0.05 . Also, key assumptions of the linear regression model (normality, linearity, homoscedasticity, and absence of multicollinearity and autocorrelation) were checked and confirmed using the approach recommended by Baños, Fonseca and Álvarez (2019).

\section{RESULTS}

\subsection{Short-Term L2 Vocabulary Learning}

To analyse whether frequency, KCR feedback and proficiency in English could predict L2 vocabulary gains in the short run (i.e., whether the number of times students encountered and identified a term as correct, along with their proficiency in English, could account for any vocabulary gains in the post-test), a linear regression was carried out including students' difference in scores between pre-test $(M=7.51, S D=3.373)$ and post-test $(M=13.64, S D=3.311)$ as the dependent variable. Overall, this model explained $45.2 \%$ of the variance $(F[3,63]=17.321, p=.000)$, although the factors 'times a term is shown' $(\beta=-.055)$ and 'proficiency in English' $(\beta=.074)$ seemed to have no significant effect on short-term vocabulary learning. Specifically, only the factor 'times a term is shown as correct' $(\beta=.248)$ had a positive influence on the learning of L2 vocabulary, as determined by the post-test (Table 3).

\subsection{Long-Term L2 Vocabulary Learning}

To ascertain whether frequency, KCR feedback and proficiency in English had any effect on longterm gains in L2 vocabulary (i.e., whether the number of times students encountered and identified a term as correct, along with their proficiency in English, could account for any vocabulary gains in the delayed test), a linear regression was carried out including students' difference in scores between pre-test $(M=7.51, S D=3.373)$ and delayed test $(M=10.82, S D=3.316)$ as the dependent variable. The regression model showed that none of the independent variables 'proficiency in English,' 'times a term is shown,' and 'times a term is shown as correct' could be used as predictors $(F[3,63]=1.084$, $p=.362$ ) (Table 4).

\section{DISCUSSION}

The first hypothesis, which anticipated that the more times a word is encountered by a player, the more likely it is to be learnt, could not be supported by the results of the study. In fact, the statistical analysis showed no significant effect of frequency either in the post-test $(p=.066)$ or in the delayed test $(p$ $=.427$ ), thus suggesting that repetition per se may not be considered a predictor of L2 vocabulary

Table 2. Pearson correlations between learning and the model variables

\begin{tabular}{|c|c|c|}
\hline Factor & Short-term & Long-term \\
\hline Proficiency in English & $.296^{*}$ & .044 \\
\hline Times a term is shown & $.269^{*}$ & .080 \\
\hline Times a term is shown as correct & $.621^{* *}$ & .198 \\
\hline Times a term is shown as incorrect & -.134 & -.035 \\
\hline Times a term is ignored & -.124 & -.101 \\
\hline
\end{tabular}

Note: $" p \leq .05, " p \leq .01, n=67$ for all analyses. 
Table 3. Influence of frequency, KCR feedback and proficiency in English on short-term L2 vocabulary learning

\begin{tabular}{|c|c|c|c|c|c|}
\hline Factor & B & SE & $\boldsymbol{\beta}$ & T & p \\
\hline (Constant) & -2.865 & 2.295 & & -1.249 & .216 \\
\hline Proficiency in English & .074 & .103 & .080 & .717 & .476 \\
\hline Times a term is shown & -.055 & .029 & -.295 & -1.868 & .066 \\
\hline Times a term is shown as correct & .248 & .047 & .817 & 5.259 & .000 \\
\hline
\end{tabular}

Note: $n=67 ; R^{2}=.452 ;$ Adjusted $R^{2}=.426 ; F(3,63)=17.321, p=.000$.

Table 4. Influence of frequency, KCR feedback and proficiency in English on long-term L2 vocabulary learning

\begin{tabular}{|c|c|c|c|c|c|}
\hline Factor & B & SE & $\boldsymbol{\beta}$ & $\mathbf{T}$ & $\mathbf{p}$ \\
\hline (Constant) & 2.348 & 1.928 & & 1.218 & .228 \\
\hline Proficiency in English & -.032 & .087 & -.054 & -.367 & .715 \\
\hline Times a term is shown & -.020 & .025 & -.166 & -.800 & .427 \\
\hline Times a term is shown as correct & .063 & .040 & .327 & 1.595 & .116 \\
\hline
\end{tabular}

Note: $n=67 ; R^{2}=.049 ;$ Adjusted $R^{2}=.004 ; F(3,63)=1.084, p=.362$.

learning. As Zahar, Cobb and Spada (2001, p. 543) state, 'part of the problem with measuring number of encounters is that word learning is incremental, so that a single encounter with a word may provide some amount of learning, while 100 encounters will still not engender a native speaker's complex knowledge of the word (its collocations, associations, and pragmatic values).' This may lead to the conclusion that although frequency has been reported to have an effect on vocabulary learning, it may be so in combination with other variables like form and meaning (see Laufer, 1990), concreteness (Crossley, Kyle, \& Salsbury, 2016), or context (see Zahar et al., 2001). In line with this, Chen and Hsu (2019, p. 11) point out that participants in their study also 'acquired words at the medium [...] and low [...] levels of frequency', ignoring whether this may be attributed to incidental learning or the 'meaningful context' provided by the game. As Webb (2008, p. 232) indicates, 'the quality of the context rather than the number of encounters with target words may have a greater effect on gaining knowledge of meaning.'

The second hypothesis, which suggested that the more times a word is identified as accurate by a student, the more likely it is to be learnt, was partially supported. So was the case in the short term, although the effect of knowledge of correct response (KCR) feedback diluted over the six weeks after the period of practice with the game. The regression model predicted $45.2 \%$ of the variance in the short run, whereas no statistical effect was found in the long run $(p=.362)$. Specifically, the beta coefficient indicated that for each 1-unit increase in the predictor variable 'times a term is shown as correct' $(\beta=.248)$, short-term L2 vocabulary learning outcomes increased by .248 units. This is in line with Ellis (2008), who identifies linguistic awareness as a pre-requisite for vocabulary learning, and with Wang, Haertel and Walberg (1990), who identify metacognitive variables as powerful predictors of learning. It seems that coming to realise that an action carried out during gameplay leads to positive outcomes may create cognitive bonds resulting in further affordances for learning. The lack of effect of knowledge of correct response (KCR) feedback on long-term L2 vocabulary learning may indicate that the pervasiveness of such cognitive bonds dilutes with time if not reinforced, as suggested by Weltens (1987).

The third hypothesis, which anticipated that the more times a word is identified as inaccurate by a student, the more likely it is to be learnt, could not be supported by the results of the study. In fact, none the of the values for the variable 'times a term is shown as incorrect' showed any significant 
correlation with short- $(p=.280)$ or long-term L2 vocabulary learning $(p=.776)$. This is in line with Ellis et al. (2006), who state that explicit feedback is clearly more effective than implicit feedback, and confirms, together with the first hypothesis, the common notion that being aware of an inaccuracy does not necessarily lead to faultlessness, and that further trial and error leading to positive feedback may be necessary for learning to happen.

However, this study does not come without limitations: First, it is assumed that each time a student performed an action while playing The Conference Interpreter full attention was being devoted to it, and therefore assimilating the consequences of such trial and error. Player absent-mindedness is therefore discarded or assumed to have no effect on the results of this study, although this was not measured during the experiment. Second, the test devised to measure L2 vocabulary learning did not consist of traditional measurement protocols such as term recognition, multiple choice, matching or cloze tests, but in the translation from English into Spanish of specialised vocabulary, which aimed to provide contextualised measures of lexical knowledge in order to demonstrate a certain degree of transferability (see Franciosi, 2017). Other measurement devices may have brought about higher scores and may have thus resulted in different effects for the predictor variables, although this needs to be analysed in further studies.

\section{CONCLUSION}

Taken together, the results of this study seem to illustrate that identifying and processing accuracies has a positive impact on the learning of foreign vocabulary, at least in the short run. On the contrary, it cannot be confirmed that receiving implicit corrective feedback leads to foreign vocabulary learning in digital game-based scenarios. However, this type feedback may lead to shifts in student behaviour, ultimately resulting in learning gains, although the nature of such affordances needs to be explored in future studies. Likewise, the results of the study indicate that the number of times a term is shown to a student is not a predictor of learning. However, it would not be appropriate to conclude that such encounters do not contribute to L2 vocabulary learning. Instead, the data may suggest that it is not frequency per se, but its affordances, which has an impact on positive learning outcomes. In other words, coming across a term on a number of occasions may not lead necessarily to its learning, but may activate simultaneous cognitive processes such as decoding, predicting, analogy-making, and so forth. It might also be the case that other variables may have a greater impact when in combination with the predictor variable frequency, as the literature seems to suggest (see Laufer, 1990; Nation, 2001; Nation \& Gu, 2007). All in all, as Zahar et al. (2001, p. 543) put it, 'it seems safe to say that there have been no definitive studies that show how many exposures to a word are needed to promote its learning.'

In conclusion, the findings bring about different implications for educators and practitioners. First, they highlight the importance of knowledge of correct response (KCR) feedback in digital game-based language learning and advocate for strategies leading to cognitive bonds between action and performance. Second, they question the relevance of repetition in L2 vocabulary learning if void of meaningful context. Ultimately, they support the notion that deploying video games in educational settings may be an adequate means to facilitate learning of L2 vocabulary and may provide meaningful affordances for the acquisition of contents adequately embedded in game dynamics.

\section{STATEMENT ON OPEN DATA, ETHICS AND CONFLICT OF INTEREST}

A copy of The Conference Interpreter video game can be downloaded for educational purposes from hdl.handle.net/10045/39015. Furthermore, free access to the data obtained during the experiment is provided via hdl.handle.net/10045/100898. All participants' data were treated confidentially and anonymously, and stored and used in compliance with the Spanish Data Protection Act (LOPD 15/1999). All the subjects understood and agreed to their participation in the study prior to the 
beginning of the research, and were duly informed of both the purpose of the experiment and their right to withdraw at any moment therefrom. No incentive to participate in the research was used in order to avoid a bias in sampling. None of the participants in the research considered themselves to have any disability or to be in any vulnerable circumstance prior to the beginning of the study. The author reports no financial or other conflict of interest relevant to the subject of this paper. 


\section{REFERENCES}

Alcaraz-Mármol, G. (2010). The Role of Frequency in the Elementary Foreign Language Classroom. Malaysian Journal of ELT Research, 6, 167-194.

Alcaraz-Mármol, G. (2015). Dispersion and frequency: Is there any difference as regards their relation to L2 vocabulary gains? International Journal of English Studies, 15(2), 1-16. doi:10.6018/ijes/2015/2/201471

Amoia, M., Gardent, C., \& Perez-Beltrachini, L. (2011). Learning a Second Language with a Videogame. In ICT for Language Learning, Conference Proceedings 2011. Simonelli Editore.

Anderson, T., Reynolds, B. L., Yeh, X. P., \& Huang, G. Z. (2008). Video games in the English as a foreign language classroom. In Second IEEE International Conference on Digital Games and Intelligent Toys Based Education, (pp. 188-192). IEEE. doi:10.1109/DIGITEL.2008.39

Balcazar, F., Hopkins, B. L., \& Suárez, Y. (1985). A Critical, Objective Review of Performance Feedback. Journal of Organizational Behavior Management, 7(3-4), 65-89. doi:10.1300/J075v07n03_05

Baños, R. V., Fonseca, M. T., \& Álvarez, M. R. (2019). Análisis de regresión lineal múltiple con SPSS: Un ejemplo práctico. REIRE Revista d'Innovació i Recerca en Educació, 12(2), 1-10. doi:10.1344/reire2019.12.222704

Brett, A., Rothlein, L., \& Hurley, M. (1996). Vocabulary Acquisition from Listening to Stories and Explanations of Target Words. The Elementary School Journal, 96(4), 415-422. doi:10.1086/461836

Brown, C. (1993). Factors affecting the acquisition of vocabulary: Frequency and saliency of words. In T. Huckin, M. Haynes, \& J. Coady (Eds.), Second language reading and vocabulary learning (pp. 263-286). Ablex.

Calvo-Ferrer, J. R. (2017), Educational games as stand-alone learning tools and their motivational effect on L2 vocabulary acquisition and perceived learning gains. British Journal of Educational Technology, 48(2), 264-278. doi:10.1111/bjet.12387

Calvo-Ferrer, J. R., Gallego Durán, F. J., Baños Sabater, A., Reverte Bernabeu, J., Terol Sanchís, J. A., Linares Pérez, H., . . . Llorens Largo, F. (2013). The Conference Interpreter. Retrieved from http://hdl.handle. net/10045/39015

Caroux, L., Isbister, K., Le Bigot, L., \& Vibert, N. (2015). Player-video game interaction: A systematic review of current concepts. Computers in Human Behavior, 48, 366-381. doi:10.1016/j.chb.2015.01.066

Chambers, G. N. (1999). Motivating language students. Multilingual Matters.

Chen, H. J. H., \& Hsu, H. L. (2019). The impact of a serious game on vocabulary and content learning. Computer Assisted Language Learning, O(0), 1-22. doi:10.1080/09588221.2019.1593197

Chen, M. H., Tseng, W. T., \& Hsiao, T. Y. (2018). The effectiveness of digital game-based vocabulary learning: A framework-based view of meta-analysis. British Journal of Educational Technology, 49(1), 69-77. doi:10.1111/ bjet. 12526

Chiu, Y. H. (2013). Computer-assisted second language vocabulary instruction: A meta-analysis. British Journal of Educational Technology, 44(2), 52-56. doi:10.1111/j.1467-8535.2012.01342.x

Chiu, Y. H., Kao, C. W., \& Reynolds, B. L. (2012). The relative effectiveness of digital game-based learning types in English as a foreign language setting: A meta-analysis. British Journal of Educational Technology, 43(4), 104-107. doi:10.1111/j.1467-8535.2012.01295.x

Cohen, J. (1988). Statistical power analysis for the behavioral sciences. Erlbaum.

Connolly, T. M., Stansfield, M., \& Hainey, T. (2011). An alternate reality game for language learning: ARGuing for multilingual motivation. Computers \& Education, 57(1), 1389-1415. doi:10.1016/j.compedu.2011.01.009

Corbalan, G., Kester, L., \& van Merriënboer, J. J. G. (2009). Dynamic task selection: Effects of feedback and learner control on efficiency and motivation. Learning and Instruction, 19(6), 455-465. doi:10.1016/j. learninstruc.2008.07.002

Cornillie, F., Clarebout, G., \& Desmet, P. (2012). The role of feedback in foreign language learning through digital role playing games. Procedia: Social and Behavioral Sciences, 34, 49-53. doi:10.1016/j.sbspro.2012.02.011 
Crossley, S., Kyle, K., \& Salsbury, T. (2016). A Usage-Based Investigation of L2 Lexical Acquisition: The Role of Input and Output. Modern Language Journal, 100(3), 702-715. doi:10.1111/modl.12344

Earl, L. L. (1970). Experiments in automatic extracting and indexing. Information Storage and Retrieval, 6(4), 313-330. doi:10.1016/0020-0271(70)90025-2

Elgort, I. (2018). Technology-mediated second language vocabulary development: A review of trends in research methodology. CALICO Journal, 35(1), 1-29. doi:10.1558/cj.34554

Ellis, N. C., \& Beaton, A. (1993). Psycholinguistic Determinants of Foreign Language Vocabulary Learning. Language Learning, 43(4), 559-617. doi:10.1111/j.1467-1770.1993.tb00627.x

Ellis, R. (2008). The study of second language acquisition. Oxford University Press.

Ellis, R., Loewen, S., \& Erlam, R. (2006). Implicit and explicit corrective feedback and the acquisition of L2 grammar. Studies in Second Language Acquisition, 28(2), 339-368. doi:10.1017/S0272263106060141

Faul, F., Erdfelder, E., Buchner, A., \& Lang, A. G. (2009). Statistical power analyses using G*Power 3.1: Tests for correlation and regression analyses. Behavior Research Methods, 41(4), 1149-1160. doi:10.3758/ BRM.41.4.1149 PMID:19897823

Franciosi, S. J. (2017). The effect of computer game-based learning on vocabulary transferability. Journal of Educational Technology \& Society, 20(1), 123-133.

Fu, F. L., Su, R. C., \& Yu, S. C. (2009). EGameFlow: A scale to measure learners' enjoyment of e-learning games. Computers \& Education, 52(1), 101-112. doi:10.1016/j.compedu.2008.07.004

Gardner, R. C., Moorcroft, R., \& Metforda, J. (1989). Second Language Learning in an Immersion Programme: Factors Influencing Acquisition and Retention. Journal of Language and Social Psychology, 8(5), 287-305. doi: $10.1177 / 0261927 \times 8985002$

Godwin-Jones, R. (2018). Contextualized vocabulary learning. Language Learning \& Technology, 22(3), 1-19.

Grabe, W., \& Stoller, F. L. (1997). Content-based instruction: Research foundations. In T. A. Snow \& D. T. Brinton (Eds.), The content-based classroom: Perspectives on integrating language and content (pp. 5-21). Longman.

Gunter, G. A., Kenny, R. F., \& Vick, E. H. (2008). Taking educational games seriously: Using the RETAIN model to design endogenous fantasy into standalone educational games. Educational Technology Research and Development, 56(5-6), 511-537. doi:10.1007/s11423-007-9073-2

Herman, P. A., Anderson, R. C., Pearson, P. D., \& Nagy, W. E. (1987). Incidental acquisition of word meaning from expositions with varied text features. Reading Research Quarterly, 22(3), 263-284. doi:10.2307/747968

Hitosugi, C. I., Schmidt, M., \& Hayashi, K. (2014). Digital game-based learning in the L2 classroom: The impact of the UN's off-the-shelf videogame, Food Force, on learner affect and vocabulary retention. CALICO Journal, 3l(1), 19-39. doi:10.11139/cj.31.1.19-39

Hung, H. T., Yang, J. C., Hwang, G. J., Chu, H. C., \& Wang, C. C. (2018). A scoping review of research on digital game-based language learning. Computers \& Education, 126(0123456789), 89-104. doi:10.1016/j. compedu.2018.07.001

Huyen, N. T. T., \& Nga, K. T. T. (2003). Learning vocabulary through games. Asian EFL Journal, 5(4), 1829-1841.

Hwang, G.-J., \& Wang, S.-Y. (2016). Single loop or double loop learning: English vocabulary learning performance and behavior of students in situated computer games with different guiding strategies. Computers \& Education, 102, 188-201. doi:10.1016/j.compedu.2016.07.005

Illanas Vila, A., Calvo-Ferrer, J. R., Gallego Durán, F. J., \& Llorens Largo, F. (2013). Predicting Student Performance in Foreign Languages with a Serious Game. In Conference Proceedings INTED 2013. International Association of Technology, Education and Development.

Jenkins, J. R., Stein, M. L., \& Wysocki, K. (1984). Learning vocabulary through reading. American Educational Research Journal, 21(4), 767-787. doi:10.3102/00028312021004767 
Kageura, K., \& Umino, B. (1996). Methods of automatic term recognition: A review. TerminologyTerminology International Journal of Theoretical and Applied Issues in Specialized Communication, 3(2), 259-289. doi:10.1075/term.3.2.03kag

Keller, J. M. (1987). Development and use of the ARCS model of instructional design. Journal of Instructional Development, 10(3), 2-10. doi:10.1007/BF02905780

Kim, J. H. (2004). Issues of Corrective Feedback in Second Language Acquisition. Working Papers in TESOL \& Applied Linguistics, 4(2), 1-24.

Kluger, A. N., \& DeNisi, A. (1996). The effects of feedback interventions on performance: A historical review, a meta-analysis, and a preliminary feedback intervention theory. Psychological Bulletin, 119(2), 254-284. doi:10.1037/0033-2909.119.2.254

Koster, R. (2005). A Theory of Fun for Game Design. Paraglyph Press, Inc.

Latham, G. P., \& Locke, E. A. (1991). Self-regulation through goal setting. Organizational Behavior and Human Decision Processes, 50(2), 212-247. doi:10.1016/0749-5978(91)90021-K

Laufer, B. (1990). Why are some words more difficult than others? - some intralexical factors that affect the learning of words. IRAL -. International Review of Applied Linguistics in Language Teaching, 28(4), 293-308. doi:10.1515/iral.1990.28.4.293

Li, S. (2010). The Effectiveness of Corrective Feedback in SLA: A Meta-Analysis. Language Learning, 60(2), 309-365. doi:10.1111/j.1467-9922.2010.00561.x

Li, Z., \& Chiu, C.-C. (2011). Adolescent ESL Students' Second Language Literacy Engagement in World of Warcraft (WoW). American Education Research Association.

Liu, M., Rosenblum, J. A., Horton, L., \& Kang, J. (2014). Designing Science Learning with Game-Based Approaches. Computers in the Schools, 31(1-2), 84-102. Advance online publication. doi:10.1080/07380569 .2014 .879776

Malone, T. W. (1981). Toward a theory of intrinsically motivating instruction. Cognitive Science, 5(4), 333-369. doi:10.1207/s15516709cog0504_2

Mason, B., \& Krashen, S. (1997). Extensive reading in English as a foreign language. System, 25(1), 91-102. doi:10.1016/S0346-251X(96)00063-2

Mayo, M. J. J. (2007). Games for science and engineering education. Communications of the ACM, 50(7), 31-35. doi: $10.1145 / 1272516.1272536$

McCarthy, M. J. (1990). Vocabulary. Oxford University Press.

Meara, P. (1992), EFL Vocabulary Tests. Lognostics.

Melchor-Couto, S. (2017). Foreign language anxiety levels in Second Life oral interaction. ReCALL, 29(01), 99-119. doi:10.1017/S0958344016000185

Miller, M., \& Hegelheimer, V. (2006). The SIMs meet ESL: Incorporating authentic computer simulation games into the language classroom. Interactive Technology and Smart Education, 3(4), 311-328. doi: $10.1108 / 17415650680000070$

Milton, J. (2009). Measuring second language vocabulary acquisition. Multilingual Matters. doi: $10.21832 / 9781847692092$

Mitchell, F. (2001). Training liason interpreters in the classroom. In S. Cunico (Ed.), Training Translators and Interpreters in the New Milennium (pp. 1-8). University of Portsmouth: School of Languages and Areas Studies.

Nation, I. S. P. (2001). Learning Vocabulary in Another Language. Cambridge University Press. doi:10.1017/ CBO9781139524759

Nation, I. S. P., \& Gu, P. (2007). Focus on Vocabulary. NCELTR. 
Nemitcheva, N. (1995). The psychologist and games in the intensive foreign language game-based course. In K. Arai \& D. Crookall (Eds.), Simulation and gaming across disciplines and cultures (pp. 70-74). Sage Publications, Inc.

Nesselhauf, N., \& Tschichold, C. (2002). Collocations in CALL: An investigation of vocabulary-building software for EFL. Computer Assisted Language Learning, 15(3), 251-279. doi:10.1076/call.15.3.251.8190

Pazienza, M. T., Pennacchiotti, M., \& Zanzotto, F. M. (2006). Terminology Extraction: An Analysis of Linguistic and Statistical Approaches. Knowledge Mining, 279(2005), 255-279. 10.1007/3-540-32394-5_20

Pérez-Luzardo Díaz, J. (2005). Competencias del intérprete simultáneo. In G. R. Navarro Montesdeoca, A. M. Monteverde Rey, V. M. González Ruiz, \& L. Cruz García (Eds.), Traducir e interpretar: visiones, obsesiones y propuestas (pp. 241-255). Universidad de Las Palmas de Gran Canaria: Servicio de publicaciones.

Price, M., Handley, K., Millar, J., \& O'Donovan, B. (2010). Feedback: All that effort, but what is the effect? Assessment \& Evaluation in Higher Education, 35(3), 277-289. doi:10.1080/02602930903541007

Rama, P. S., Black, R. W., van Es, E., \& Warschauer, M. (2012). Affordances for second language learning in World of Warcraft. ReCALL, 24(3), 322-338. doi:10.1017/S0958344012000171

Ranalli, J. (2008). Learning English with the Sims: Exploiting authentic computer simulation games for L2 learning. Computer Assisted Language Learning, 21(5), 441-455. doi:10.1080/09588220802447859

Reinders, H., \& Wattana, S. (2011). Learn English or die: The effects of digital games on interaction and willingness to communicate in a foreign language. Digital Culture \& Education, 3(1), 3-28.

Reinhardt, J. (2017). Digital Gaming in L2 Teaching and Learning. The Handbook of Technology and Second Language Teaching and Learning, 202-216. doi:10.1002/9781118914069.ch14

Reinhardt, J. (2019). Gameful Second and Foreign Language Teaching and Learning: Theory. Research and Practice. doi:10.1007/978-3-030-04729-0

Restrepo Ramos, F. D. (2015). Incidental Vocabulary Learning in Second Language Acquisition: A Literature Review. PROFILE Issues in Teachers'. Professional Development, 17(1), 157-166. doi:10.15446/profile. v17n1.43957

Ricci, K. E., Salas, E., \& Cannon-Bowers, J. A. (1996). Do Computer-Based Games Facilitate Knowledge Acquisition and Retention? Military Psychology, 8(4), 295-307. doi:10.1207/s15327876mp0804_3

Rivers, W. M. (1983). Communicating Naturally in a Second Language. Oxford University Press.

Rott, S. (1999). The effect of exposure frequency on intermediate language learners' incidental vocabulary acquisition and retention through reading. Studies in Second Language Acquisition, 2 (4), 589-619. doi:10.1017/ S0272263199004039

Russell, J., \& Spada, N. (2006). The effectiveness of corrective feedback for the acquisition of L2 grammar. Synthesizing Research on Language Learning and Teaching. doi:10.1075/111t.13

Salen, K., \& Zimmerman, E. (2004). The rules of play: Game design fundamentals. MIT Press.

Sandberg, J., Maris, M., \& Hoogendoorn, P. (2014). The added value of a gaming context and intelligent adaptation for a mobile learning application for vocabulary learning. Computers \& Education, 76, 119-130. doi:10.1016/j.compedu.2014.03.006

Saragi, T., Nation, P., \& Meister, G. (1978). Vocabulary learning and reading. System, 6(2), 72-80. doi:10.1016/0346-251X(78)90027-1

Schell, J. (2008). The Art of Game Design: A book of lenses. Morgan Kaufmann. doi:10.1201/9780080919171

Schmitt, N. (2008). Instructed second language vocabulary learning. Language Teaching Research, 12(3), 329-363. doi: $10.1177 / 1362168808089921$

Schrader, P. G., \& McCreery, M. (2008). The Acquisition of Skill and Expertise in Massively Multiplayer Online Games. Educational Technology Research and Development, 56(5), 557-574. doi:10.1007/s11423-007-9055-4 
Schwienhorst, K. (2002). Why virtual, why environments? Implementing virtual reality concepts in computerassisted language learning. Simulation \& Gaming, 33(2), 196-209. doi:10.1177/1046878102332008

Shute, V. J. (2008). Focus on Formative Feedback. Review of Educational Research, 78(1), 153-189. doi: $10.3102 / 0034654307313795$

Skiba, D. J. (2008). Emerging Technologies Center: Games for Health. Nursing Education Perspectives, 29(4), 230-232. PMID: 18770953

Sundqvist, P. (2009). Extramural English matters: Out-of-school English and its impact on Swedish ninth graders oral proficiency and vocabulary. Faculty of Arts and Education, English, Karlstads Universitet.

Sykes, J. M., \& Reinhardt, J. (2012). Language at Play: Digital Games in Second and Foreign Language Teaching and Learning. Pearson.

Sylvén, L. K., \& Sundqvist, P. (2012). Gaming as extramural English L2 learning and L2 proficiency among young learners. ReCALL, 24(3), 302-321. doi:10.1017/S095834401200016X

Tsai, Y. L., \& Tsai, C. C. (2018). Digital game-based second-language vocabulary learning and conditions of research designs: A meta-analysis study. Computers \& Education, 125(June), 345-357. doi:10.1016/j. compedu.2018.06.020

Vermeer, A. (1992). Exploring the second language learner lexicon. In L. Verhoeven \& J. H. A. L. de Jong (Eds.), The construct of language proficiency (pp. 147-162). doi:10.1075/z.62.16ver

Wang, M. C., Haertel, G. D., \& Walberg, H. J. (1990). What influences learning? A content analysis of review literature. The Journal of Educational Research, 84(1), 30-43. doi:10.1080/00220671.1990.10885988

Warburton, S. (2009). Second Life in Higher Education: Assessing the Potential for and the Barriers to Deploying Virtual Worlds in Learning and Teaching. British Journal of Educational Technology, 40(3), 414-426. doi: $10.1111 / \mathrm{j} .1467-8535.2009 .00952 . x$

Webb, S. (2008). The effects of context on incidental vocabulary learning. Reading in a Foreign Language, $20(2), 232-245$.

Weltens, B. (1987). The attrition of foreign-language skills: A literature review. Applied Linguistics, 8(1), 22-37. doi:10.1093/applin/8.1.22

Whitehill, B. V., \& McDonald, B. A. (1993). Improving Learning Persistence of Military Personnel by Enhancing Motivation in a Technical Training Program. Simulation \& Gaming, 24(3), 294-313. doi: $10.1177 / 1046878193243002$

Xu, Z., Chen, Z., Eutsler, L., Geng, Z., \& Kogut, A. (2019). A scoping review of digital game-based technology on English language learning. Educational Technology Research and Development, 1-28. doi:10.1007/s11423019-09702-2

Yip, F. W. M., \& Kwan, A. C. M. (2006). Online vocabulary games as a tool for teaching and learning English vocabulary. Educational Media International, 43(3), 233-249. doi:10.1080/09523980600641445

Zahar, R., Cobb, T., \& Spada, N. (2001). Acquiring vocabulary through reading: Effects of frequency and contextual richness. Canadian Modern Language Review, 57(5), 541-572. doi:10.3138/cmlr.57.4.541

\section{ENDNOTES}

A version for educational use of the video game The Conference Interpreter including the texts and terms it contains can be accessed from http://hdl.handle.net/10045/39015.

Retrieved from https://www.cambridgeenglish.org/test-your-english/. 


\section{APPENDIX: KNOWLEDGE TEST}

Please provide a translation for each of the terms in bold below:

API:

E.g.: It shares the same system APIs as you would find in LINUX or OSX.

Bezel:

E.g.: So it seems like they have sorted out this white bezel problem.

Border:

E.g.: Now, sometimes you get a red border when you do something that can't be done.

Browser:

E.g.: The Honeycomb browser improves upon the already good rendering fidelity of the Android browser.

To come stock:

E.g.: These programmes don't come stock on your device.

Core:

E.g.: We take the lead with dual core processors for real, true multitasking capability.

CPU:

E.g.: It's going to give us something that's up to twice as fast on $C P U$ performance, up to nine times faster on graphics.

EAL:

E.g.: We have the highest level of security certifications, $E A L$ level $4+$.

Emulator:

E.g.: Google recently released the Honeycomb preview SDK, which allows us to run the emulator and actually use Honeycomb.

\section{Landscape:}

E.g.: In landscape mode you are going to see two panes.

Manager:

E.g.: We're gonna see the new and improved homescreen manager.

Multitasking:

E.g.: We take the lead with dual core processors for real, true multitasking capability.

OEM:

E.g.: It's going to give the $O E M s$ a lot of flexibility in how they want to design their hardware.

Port:

E.g.: Shame it's not a port, but they are supplying a cable.

\section{Preview:}

E.g.: You can see a preview of what it looks like.

Processor:

E.g.: We all expected it, it's got an all new design, this includes a new A5 processor.

To release:

E.g.: Google recently released the Honeycomb preview SDK, which allows us to run the emulator and actually use Honeycomb.

Rendering:

E.g.: The Honeycomb browser improves upon the already good rendering fidelity of the Android browser.

To run:

E.g.: Google recently released the Honeycomb preview SDK, which allows us to run the emulator and actually use Honeycomb.

SDK: 
E.g.: Google recently released the Honeycomb preview SDK, which allows us to run the emulator and actually use Honeycomb.

\section{Shortcut:}

E.g.: So if we tap Shortcuts we will get a list of all the applications on your phone.

To stream:

E.g.: You may not just locally play, but stream your content with Airplay.

UI:

E.g.: We think this is really cool new $U I$ and hopefully you'll love it.

Unlock:

E.g.: So, first, [there is] a new unlock screen, for better or for worse.

Widget:

E.g.: So, we just tried to add a widget, didn't work.

José Ramón Calvo-Ferrer holds a PhD in Translation and Interpreting from the Universidad de Alicante, where he teaches different modules on Translation, English, and teacher training since 2008. His research interests lie in ICT in general and video games in particular for second language learning and translator training. He has published various papers on video games, multimodality and second language learning in top-ranked journals and is a Visiting Lecturer at the Department of Language of Linguistics of the University of Essex, where he delivers lectures and workshops on video games and translation. 